\title{
RENAL PARENCHYMAL MALACOPLAKIA WITH PLEURAL EFFUSION
}

José Cury, Rafael Ferreira Coelho, Marcello Franco, Miguel Srougi

\section{INTRODUCTION}

Malacoplakia is an unusual inflammatory disease originally described as affecting the bladder but has since been found to affect the genitourinary and gastrointestinal tracts, skin, lungs, bones, and mesenteric lymph nodes. Patients with genitourinary malacoplakia often have chronic coliform bacteriuria, and treatment should be directed to control urinary infections, a procedure which should stabilize the disease process. Clinical presentation includes fever, flank pain, and palpable mass, particularly in patients with perinephric extension. ${ }^{1}$ A case of renal malacoplakia with pleural effusion as the clinical manifestation and its management is reported.

\section{CASE REPORT}

A 42-year-old African Brazilian woman presented to our service complaining of right lumbar pain for 3 months, which had worsened in the last 2 weeks, and a weight loss of $26 \mathrm{~kg}$ over the 3 month period. She had been a smoker for 25 years and had a past history of acute pyelonephritis that was clinically treated at the age of 10 years, and a severe anaphylactic reaction to contrast media in a prior excretory urography performed in another institution. Physical examination revealed a hard and painful right flank mass. The hemoglobin level was $7 \mathrm{mg} / \mathrm{dL}$, white blood cell count was $17000 / \mathrm{mm}^{3}$, and serum creatinine was $1.1 \mathrm{mg} /$ $\mathrm{dL}$. Urinalysis revealed proteinuria $(1.64 \mathrm{~g} / \mathrm{dL})$ and pyuria (> 2 million white cells). A small right pleural effusion was observed on chest $\mathrm{x}$-ray. Abdominal ultrasound detected a $10 \times 9 \mathrm{~cm}$ complex solid mass in the right kidney, and magnetic resonance imaging of the kidneys revealed a soft tissue mass in the middle and lower portions of the right kid-

Department of Urology, São Paulo University Medical School - São Paulo/ SP, Brazil.

Email: jc_uro@osite.com.br ney that had an intermediate heterogeneous signal in SE T1 images. The injection of paramagnetic contrast media revealed a homogenous enhancement of the anterior aspect of the right renal mass and thin septa delineating multiple hyposignal fluid cavities (Figure 1). A thoracocentesis was performed, and $300 \mathrm{~mL}$ of pus was removed from her right chest, but there was no bacterial growth in the culture. Antibiotic therapy ( $2.0 \mathrm{gr} /$ day of ceftriaxone) was given, and a right nephrectomy was performed through a right lombotomy. This ressected kidney weighed $425 \mathrm{~g}$ and measured $13 \times 8 \times 8 \mathrm{~cm}$ in diameter. Histological sections showed that within the histiocytes (von Hansermann's cells) and also extracellularly in the stroma, there were rounded, concentrically layered, target or ring-like structures that reacted positively to periodic Schiff reagent with and without diastase predigestion, as well as positivity for calcium (Von Kossa); these structures were interpreted to be Michaelis-Gutmann bodies (Figures 2-A and B). Taken together, these findings were interpreted as renal involvement by malakoplakia. In addition, pyonephrosis and chronic contraction of the remnant renal parenchyma were also observed. She had an uneventful recovery from the surgery.

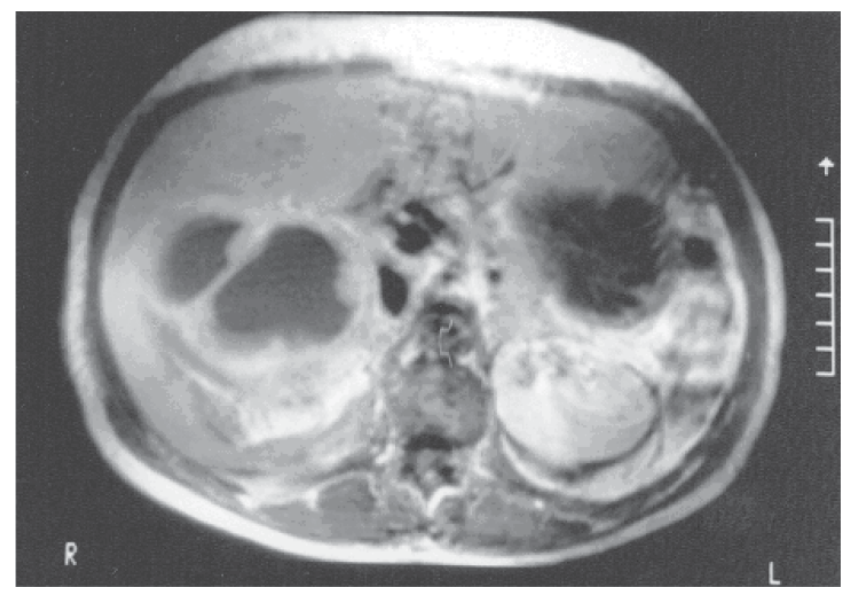

Figure 1 - Magnetic Resonance Imaging revealing a soft tissue mass in the right kidney 

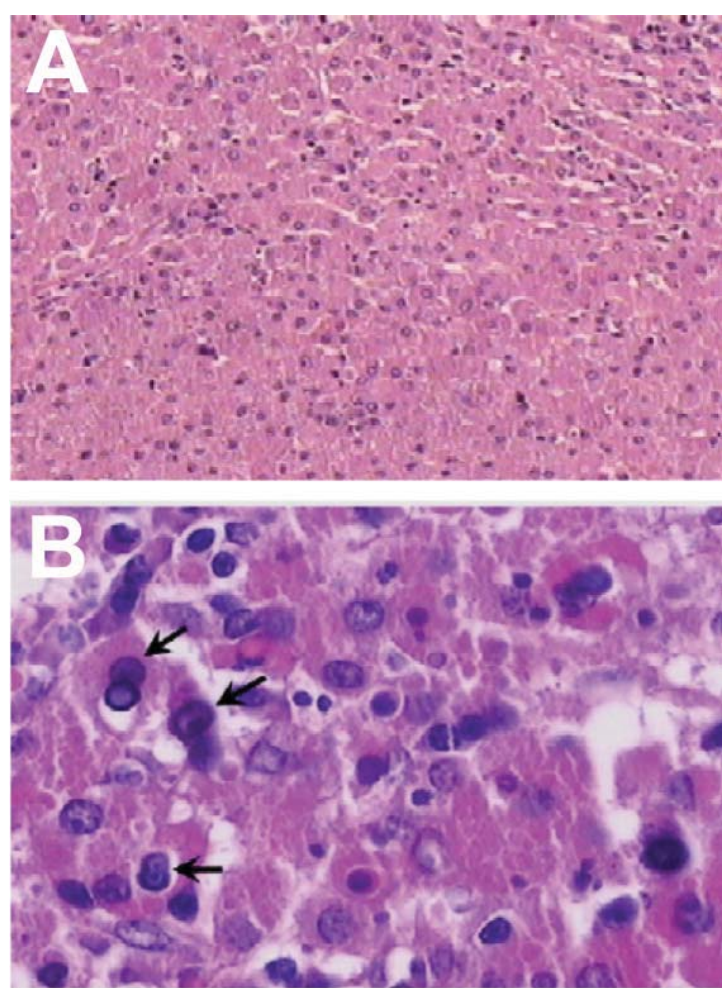

Figure 2 - (A) large macrophage cells with eosinophilic cytoplasm (histiocytes). (B) within the histiocytes as well as extracellularly in the stroma, rounded, concentrically layered, target or ring-like structures that were interpreted as Michaelis-Guttman bodies (arrows) H\&E 400x.

\section{DISCUSSION}

Malacoplakia was first described by Michaelis and Guttmann in 1902. It is a granulomatous disease that affects many tissues but most frequently involves the urinary tract. ${ }^{1}$ There is a female predominance when the urinary tract is involved, which occurs at peak incidence in the fourth and fifth decade of life., ${ }^{2,3}$ Of the 153 cases reviewed from the literature by Stanton \& Maxted, ${ }^{1}$ renal parenchymal malakoplakia accounted for $16 \%$ of them. The clinical presentation of renal malacoplakia includes fever, flank pain, and palpable mass, particularly in patients with perinephric extension, ${ }^{2,3}$ and $E$. coli urinary infection is frequently associated. ${ }^{2,3}$ Malacoplakia is described as a chronic infection that is histologically characterized by histiocytes containing distinct basophilic inclusions called MichaellisGutmann bodies, which are believed to result from abnormal macrophage function; these inclusions are calcifications around incompletely digested bacteria. ${ }^{1-3}$ Differential diagnosis by radiological examination includes local abscess and granulomas, xantogranulomatous pyelonephrites, lymphoma, or multifocal primary or metastatic tumors. Long-term antibiotic therapy and surgical resection is performed if there is progression of the disease despite appropriate medical treatment.

\section{REFERENCES}

1. Stanton MJ, Maxted W. Malacoplakia. A study of the literature and current concepts of pathogenesis, diagnosis and treatment. J Urol.1981;125:139.

2. Hartmann DS, Davis CJ Jr, Lichtenstein JE, Goldman SM. Renal parenchymal malakoplakia. Radiology. 1980;136:33.
3. Long JP Jr, Althausen AF. Malacoplakia: a 25-year experience with a review of the literature. J Urol. 1989;141:1328. 